\title{
Main Adaptation Objectives among Adolescents in Different Internal Disorder Pattern Variants
}

\author{
Tatiana N. Adeeva * (a), Inna V. Tikhonova (b) \\ (a), (b) Kostroma State University, 156005, Kostroma (Russia), 17 Dzerzhinskogo street, \\ adeeva.tanya@rambler.ru
}

\begin{abstract}
The problem of social and psychological adaptation remains one of the most important for adolescence. It acquires far greater significance for disabled adolescent individuals whose personal development occurs under hard conditions. Dysontogenesis forms both imply information processing specificities and can determine personal development, Iconcept formation, and social adaptation features. Modern Russian and foreign studies mainly focus on the following determinants of disabled people's social adaptation: personal traits, social living conditions, and the severity of their disorder. In this light, academic research on socio-psychological adaptation determinants among adolescents proves critical. Those are traditionally associated with disorder severity and an individual's age their disorder occurred. We consider the internal disorder pattern (IDP), which is an integrative formation understood as a complex of sensations, knowledge, experiences, and motivational shifts associated with the disorder, one of the crucial factors for successful adaptation as well. We observe a lack of consistency in the research background of the IDP phenomenon.

Our results reveal that one's disorder awareness, emotional experiences, physical sensations caused by his disorder, and subsequent health limitations may affect their adaptability.

We distinguish 4 IDP variants whose components may differ quantitatively as well as in their ratio. Each IDP component has specific relationships with social-psychological adaptation parameters. Most successful adaptation strategies are correlated to low indices in the physical-sensitive IDP component. The results also suggest several hypotheses about possible adaptation and maladaptation mechanisms.
\end{abstract}

Keywords: adolescents, socio-psychological adaptation, limited health opportunities, inward disorder pattern.

(C) 2021 Tatiana N. Adeeva, Inna V. Tikhonova

This is an open access article distributed under the terms of the Creative Commons Attribution License (CC BY 4.0), which permits unrestricted use, distribution, and reproduction in any medium, provided the original author and source are credited.

Published by Kazan federal university and peer-reviewed under responsibility of IFTE-2021 (VII International Forum on Teacher Education)

*Corresponding author. E-mail: adeeva.tanya@rambler.ru 


\section{Introduction}

Social-psychological adaptation of adolescents remains one of the most acute problems of this age period. It gains far greater significance for disabled adolescents whose personal development occurs under hard conditions. Any dysontogenesis form both implies information processing specificities and can determine personal development, I-concept formation, and social adaptation features. Modern Russian and foreign studies focus on the factors of disabled people's social adaptation: personal traits, social living conditions, and the severity of their disorder. Inward disorder pattern (IDP) might be one of the crucial adaptation factors. It is a complex integrative construct; a scope of feelings, knowledge, emotional experience and motivational shifts caused by or related to a disorder.

\section{Purpose and objectives of the study}

The aim of the research is to identify social-psychological adaptation specificities among disabled adolescents which are related to IDP features; to define the objectives of psychological and pedagogical support for adolescents with challenged adaptation.

\section{Literature review}

Personal traits are one of the crucial factors in adolescents' successful social-psychological adaptation. Various researchers stress this significance. Self-esteem level, adequate assessment of oneself, and an individual's ambitions appear to play an important role in disabled adolescents' adaptation. Self-esteem and I-concept specificities affect their social contacts development and communication patterns (Dunayevskaya, 2016; Hyeran \& Sunhee 2019; Adeeva, Tikhonova \& Khazova, 2019). Self-acceptance and self-confidence are of considerable relevance for adolescents with hearing and locomotor disabilities. Intrapersonal conflict is a characteristic of those with musculoskeletal disorders (Akinina, 2015; Katsero, 2019; Voronova \& Gudzovskaya, 2020).

Dysontogenesis form and its severity are important determinants of adaptation (Shorey \& Debby, 2020). High anxiety, low self-esteem and social phobias are typical for adolescents with intellectual disability, delayed mental development, or psychiatric diagnoses (Koneva \& Kuznetsova, 2015; O'Connor, Kadianaki, Maunder \& McNicholas, 2018). Adolescents with musculoskeletal disorders demonstrate hindered acquisition of social roles, rather delayed I-concept formation, and inconsistent self-attitude (Cheong, Lang \& Johnston, 2018). Congenital disorders are related to more serious maladjustment. 
In the first instance, researchers identify the availability/unavailability of efficient social and psychological support, among other significant social factors in adaptation (Shuvalova, 2015). A disabled individual's and their family's access to a system of social-psychological support suggests successful socialisation and prevents negative developments in one's personality. At present, the relationship between school educational methods and successful adaptation is a central issue. The interconnection between inclusive education and adaptation parameters provides diverse and rather contradictory data (Roorda, Zee, Bosman, \& Koomen 2021). Family system and family relationships specificities are also in the focus of academic research on disabled adolescents' social-psychological adaptation. The family is considered a primary group in which social adaptation takes place (Ramirez \& Heredia, 2017).

Modern studies on the IDP phenomenon lack sufficient research. However, IDP may affect one's choice of behavior pattern for different situations and may also determine their preference for certain adaptive strategies. Disorder phenomenon can be interpreted from two aspects. The first one is medical-biological: disorder is understood as a persistent complex of symptoms, including deficit disorders and bodily and psychological compensatory mechanisms. The compensation process is related to a shift in body functional systems' performance. The shift is limited to health and general human body potential. Lost and impaired bodily functions can be compensated to different degrees and in different ways, though this process implies the significance of external support or stimuli. Compensation is critical for an individual's successful sociopsychological adaptation. Adults can create an environment crucial and favorable for disabled children to develop effective compensatory mechanisms. The emotional and cognitive components are affected by one's social environment. The second aspect of the interpretation is psychological. According to Russian scholars, disorder creates specific development conditions, «...a deviation from the regular human biological type», causes «a loss of certain functions, a lack or impairment of organs, more or less fundamental restructuring of all the organism on new bases, after a new model ...» (Vygotskij, 1983, p. 23). Traditionally, special psychology focuses on a situation of either congenital or childhood disorders. Persistent medical symptoms are related to numerous activity limitations. Personality development occurs under different, or challenged, conditions. IDP can be a determiner of particular personality traits and socio-psychological adaptation specificities.

Each ontogenesis stage of disabled people may be marked by challenged social role acquisition, social group admittance, and development of social contacts, which is related to their non-normative development patterns. In our study, we understand adaptation as a dynamic state that facilitates one's self-actualization, «does not lead to sustained conflicts and frustrations, gives an individual an opportunity to develop their 
maximum creativity and productivity, to seek self-affirmation, and understand their self-significance» (Nalchajyan, 1988, p. 26-27).

Normative adaptation does not involve pathological transformations in one's personality structure. Successful adaptation parameters include an individual's ability to efficiently function in a system of interpersonal relations; one to develop a behavioral pattern according to social standards; and that to fulfill one's current needs according to their ontogenesis stage. The external criterion implies effective functioning in a concrete environment and successful adaptation to it and is assessed according to the levels of individual's subjective satisfaction and emotional comfort. Drawing on the personality-activity approach, we introduce the third criterion - successful self-determination in a social environment, which implies one's proactive attitude to the environment (Dolgova \& Vasilenko, 2016). This criterion defines an individual's ability to set and accomplish goals, strive for creativity and achievements in the environment, and different forms of integration with it. Successful self-determination in a social environment may be observed in the following parameters: one's perception of their future and past, the meaningfulness of life, self-acceptance and that of others, and internalism.

IDP is considered a part of an individual's I-concept. It is made up of the physical (sensitive), cognitive, emotional, and motivational components. The physical one involves a complete lack / a number of an individual's physical sensations caused by their disorder. The cognitive component includes an individual's awareness of their defect, preventive measures, and defect-related health limitations (activity limitations). The emotional component implies a variant of emotional experiences created by one's disability. The motivational one implies both a total lack / high levels of an individual's motivation to overcome their defect and a shift in a traditional set of their motives caused by their disorder. At present, the IDP phenomenon is mainly studied in terms of its cognitive (one's awareness of their disorder) and emotional (one's attitude toward their disorder) components (Gaidukevich, 2011). However, an individual's physical discomfort and a level of their physical sensation are key aspects to affect an inward disorder pattern. One's vivid physical sensations (the physical-sensitive component) and motive specificities caused by a disorder may also be critical for their choice of adaptation strategies (Adeeva, Tikhonova \& Khazova, 2019). It is important to say that our respondents were adolescents. This age period is one of the most challenged ontogenesis stages and involves a dynamic development of I-concept, personal values and attitudes. It is the time when an individual experiments with various behavioral patterns in order to gain a better understanding of oneself.

\section{Methodology}


The sample comprises 109 disabled adolescents. Those with visual impairment (VI) are 24 people, with hearing impairment (HI) - 18 people, with severe speech impairment (SSI) - 37 people, with mental development disorders (MDD) - 30 people. The average age is 14 .

We used a questionnaire and an interview research methods, «Social and Psychological Adaptation Questionnaire» by K. Rogers and R. Dymond (adapted by A. Osnitsky, 2004), and the conversation technique "The Study of Internal Disorder Patter" by T. Adeeva (2018). Statistical analysis was performed using 10.0 Statistica software. We used the K-means clustering method to form clusters (Euclid distance calculation), Spearman's rank correlation coefficient was estimated, and reliability of the divergence was proved by Mood's median test.

\section{Results}

We divided the sample into 4 groups with distinctive IDPs by means of cluster analysis. The descriptions of the clusters are presented in Table 1.

Table 1. Quantitative characteristics of selected clusters.

\begin{tabular}{|c|c|c|c|c|c|c|c|c|}
\hline \multirow{2}{*}{$\begin{array}{l}\text { 1. Clust } \\
\text { er no. }\end{array}$} & \multirow[b]{2}{*}{$\begin{array}{l}\text { 2. Total } \\
\text { amount } \\
\text { (number } \\
\text { of } \\
\text { people) }\end{array}$} & \multicolumn{4}{|c|}{ 3. Nosology total (number of people) } & \multirow{2}{*}{$\begin{array}{l}\text { 4. Male } \\
5 . \text { (numb } \\
\text { er of } \\
\text { people) }\end{array}$} & \multirow[b]{2}{*}{$\begin{array}{l}\text { 6. Femal } \\
\text { e } \\
\text { 7. (numb } \\
\text { er of } \\
\text { people) }\end{array}$} & \multirow{2}{*}{$\begin{array}{l}\text { 8. Avera } \\
\text { ge age }\end{array}$} \\
\hline & & $\begin{array}{l}\text { 9. SSI } \\
10 . \text { (num } \\
\text { ber of } \\
\text { people) } \\
11 .\end{array}$ & $\begin{array}{l}\text { 12. VI } \\
\text { 13. (num } \\
\text { ber of } \\
\text { people) }\end{array}$ & $\begin{array}{l}\text { 14. MM } \\
\mathrm{D} \\
\text { 15. (num } \\
\text { ber of } \\
\text { people) }\end{array}$ & $\begin{array}{l}\text { 16. HI } \\
\text { 17. (num } \\
\text { ber of } \\
\text { people) }\end{array}$ & & & \\
\hline 18.1 & 19.41 & 20.5 & 21.13 & 22.14 & 23.9 & 24.25 & 25.16 & 26.14 .2 \\
\hline 27.2 & 28. 23 & 29.5 & 30.9 & 31.9 & 32. - & 33.15 & 34.8 & 35. 13,8 \\
\hline 36.3 & 37.27 & 38. 19 & 39.2 & 40.6 & 41. - & 42. 19 & 43.8 & 44. 13,8 \\
\hline 45.4 & 46. 18 & 47.7 & 48. 2 & 49. - & 50.9 & 51.7 & 52.11 & 53. 14,1 \\
\hline 54. total & 55.109 & 56.36 & 57. 26 & 58. 29 & 59. 18 & 60.66 & 61.43 & 62. \\
\hline
\end{tabular}

Note: visual impairments - VI; severe speech impairments - SSI; mental development disorder - MDD; hearing impairments $-\mathrm{HI}$.

The first cluster comprises 41 respondents (5 adolescents with SSI, 13 adolescents with visual impairments, 14 adolescents with DMD, 9 adolescents with hearing impairments; 16 female adolescents, 25 male adolescents). The second cluster consists of 23 respondents (5 adolescents with SSI, 9 adolescents with visual impairments, 9 adolescents with DMD; 8 female adolescents, 15 male adolescents). Their age ranges from 11 to 16 , the median one is 13.8. The third cluster includes 27 people (19 adolescents with 
SSI, 2 adolescents with visual impairment (VI), 6 adolescents with DMD; 8 female adolescents, 19 male adolescents). The respondents are in the 12-15 age group, the median age is 13.8 . Thus, this group mainly represents the SSI group and a small number of adolescents with DMD, which implies a homogeneous defect structure.

The fourth cluster is the smallest, consisting of only 18 respondents ( 9 adolescents $(50 \%)$ with hearing impairments, 7 adolescents (38.9\%) with speech impairments, only 2 adolescents (11.1\%) with visual impairments; 7 male adolescents, 11 female adolescents, the median age is 14.1). Cluster 1 is the most numerous and comprises all the nosologies of developmental disorders; almost half of adolescent respondents with MDD belong to the cluster. Cluster 3 comprises more than half of those with SSI. Cluster 4 is characterized by a prevalence of females and a total lack of MDD respondents.

The content of IDP components in the clusters is represented in Figure 1. We observed the lowest indices in the physical and sensitive $(\mathrm{M}=2.75 \mathrm{SD}=0.79)$ components in Cluster 1 . The respondents report disorderrelated sensations. About $25 \%$ of the respondents are satisfied with their health condition and mention no health limitations. The adolescent respondents are quite aware of their disorder $(\mathrm{M}=5.53 \mathrm{SD}=1.12$ in the cognitive component). All the respondents accept their disorders, feel optimistic about their health, and are able to mention ways to improve it. However, they are insufficiently aware of disorder causes, workplace, physical, or everyday activity health limitations caused by their disorders. The motivational component has medium indices on the parameters compared to the other clusters $(\mathrm{M}=3.95 \mathrm{SD}=1.26)$. Approximately $40 \%$ speak of their desire to change their health condition, to reduce disorder symptoms. One's attitude to a disorder takes two forms. The respondents mainly tend to ignore their defects. Roughly $17 \%$ feels anxious about them. Cluster 2 has fairly high indices of all the IDP components: the physical-sensitive (M=5.78; $\mathrm{SD}=1.13)$, the cognitive $(\mathrm{M}=5.3 ; \mathrm{SD}=1.22)$, the motivational $(\mathrm{M}=4.3 ; \mathrm{SD}=0,76)$, the emotional $(\mathrm{M}=5.74$; $\mathrm{SD}=1.48$ ). We can conclude that the respondents feel numerous unpleasant sensations caused by their defects and are aware of their health condition causes and limitations. They demonstrate intense emotions towards it. In general, this cluster can be considered both relatively "smooth" and "tense", with no sharp IDP indices' fluctuations. When compared to Cluster 2, Cluster 1 is contrasted by higher indices in the physical-sensitive component. The respondents often report fatigue, exhaustion after intense physical and intellectual work. We observed the following IDP specificities in Cluster 3 - approximately close indices on the physical-sensitive $(\mathrm{M}=4.92 ; \mathrm{SD}=1.14)$, the motivational $(\mathrm{M}=4.59 ; \mathrm{SD}=0.93)$, and the emotional $(\mathrm{M}=4.85 ; \mathrm{SD}=1.2)$ components. In contrast, those on the cognitive component are the lowest $(\mathrm{M}=2.37$; $\mathrm{SD}=0.84$ ) in the sample. The respondents in this cluster are characterized by a high level of sensitivity to physical sensations, report fairly intense emotional experiences, demonstrate an intention to overcome their disorder but lack any awareness of their disorder, activity limitations, and disorder deterioration preventive measures. The fourth cluster is characterized by low (below-average) indices in the IDP components. In 
contrast with the other clusters, the motivational $(\mathrm{M}=2.22, \mathrm{SD}=1.21)$ and the emotional $(\mathrm{M}=3.72$, $\mathrm{SD}=1.36$ ) components have the lowest indices. The respondents seem to display a rather positive attitude to their defect and to recognize no need to overcome. Nevertheless, the results require further investigation.

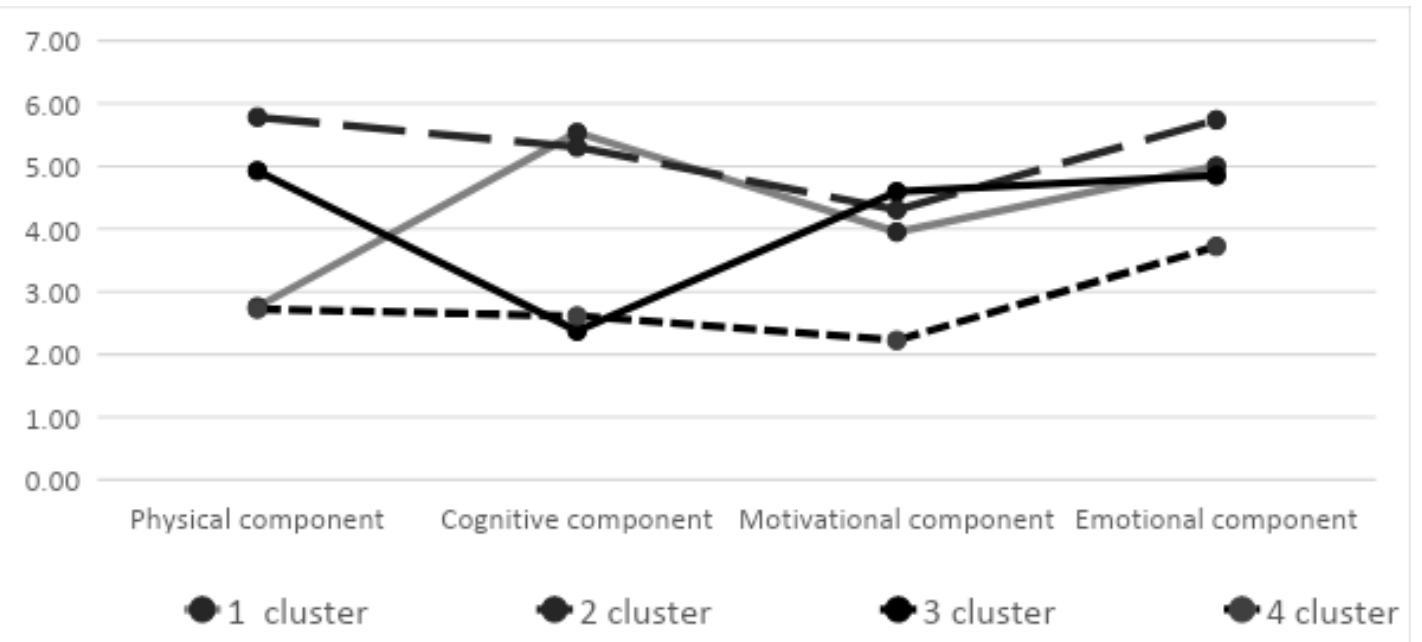

Figure 1. Indicators of the severity of the components of the Inward Disorder Pattern in the selected clusters.

Using "Social and Psychological Adaptation Questionnaire” by K. Rogers and R. Dymond, we obtained statistically significant divergences on such social-psychological adaptation parameters as maladaptation and self-rejection (Table 2).

Table 2. Indicators of socio-psychological adaptation with significant differences (median test)

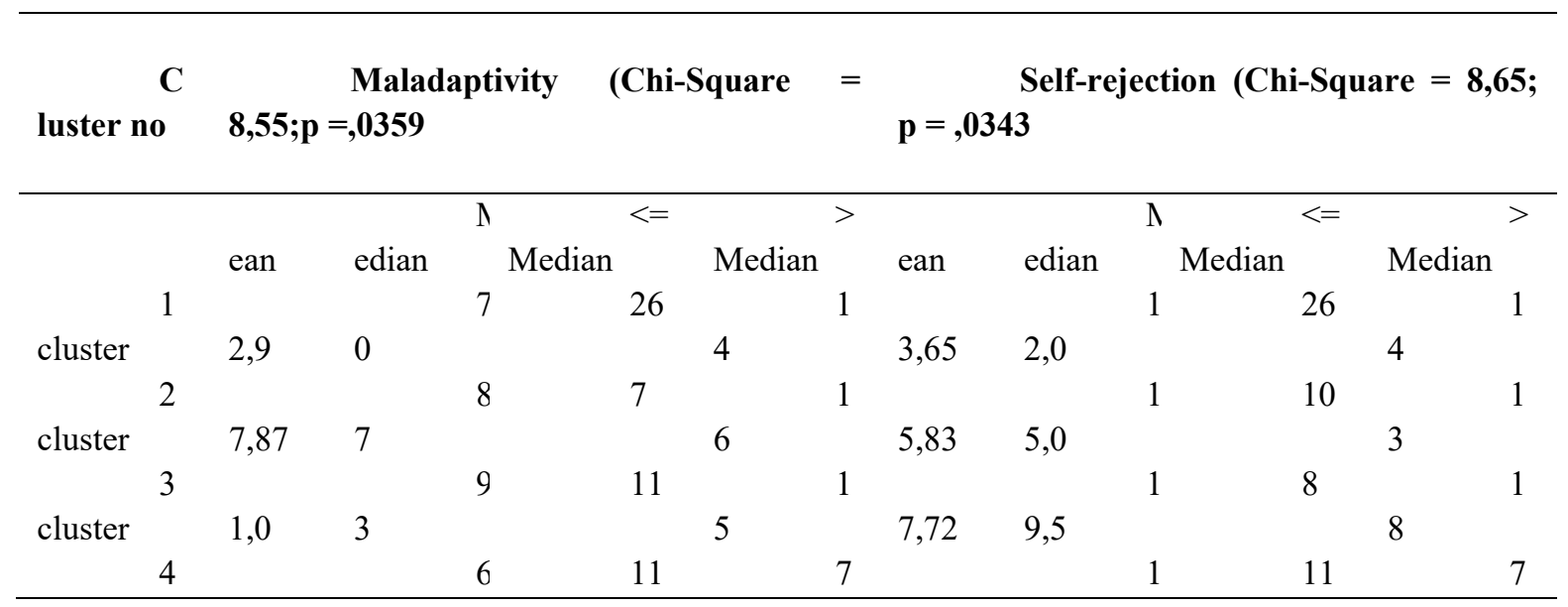


$\begin{array}{lllll}\text { cluster } & 0,78 & 1 & 2,72 & 0,5\end{array}$

The indices in each cluster calculated by means of the maladaptation scale indicate moderately challenged social adaptation and fulfilment of goals in society. Cluster 1, which is most perfectly aware of their disorders, denies their physical discomfort but experiences a range of emotional states related to their impairment, is the least likely to report adaptation and goal challenges.

Clusters 2 and 3 are the most susceptible to maladaptive reactions and states. Excessive sensitivity to their own bodies and fixation on physical sensations are common for the two clusters. Self-rejection is also observed in Clusters 2 and 3. The indices on this parameter are of average value (14-35) and indicate dissatisfaction with oneself and their personal traits.

The results of the correlation analysis reveal the correlations between IDP components values and socialpsychological adaptation parameters in each cluster. The most significant correlation is found in Cluster 1 (Table 3) - the motivational and the emotional IDP components prove crucial for an individual's successful adaptation.

Table 3. Correlations between social adaptation parameters and IDP components among disabled adolescents, cluster $1(\mathrm{p}<0,05)$

\begin{tabular}{lccc}
\hline Adaptation parameters & Cognitiv & Motivational & Emotion \\
\hline Adaptation & e & & $-0,36$ \\
Self-acceptance & & $-0,46$ & $-0,32$ \\
Acceptance of others & & $-0,50$ & $-0,46$ \\
Emotional comfort & & $-0,33$ & \\
Internality & 0,32 & $-0,39$ & $-0,45$ \\
Dominance behavior & $-0,42$ & \\
\hline
\end{tabular}

We discovered negative correlations between such adaptation parameters as self-acceptance, acceptance of others, emotional comfort, internality, dominance behavior, and adaptation itself and an individual's efforts to overcome their disorder. We also discovered those between levels of one's adaptation, emotional comfort, self-acceptance and the emotional component which demonstrates the intensity of emotional experiences that are related to a disorder. The cognitive IDP component is positively correlated to one's dominance behavior in Clusters 1 and 2 (Tables 3 and 4). The correlations between IDP and adaptation itself are insignificant in Clusters 2, 3, 4 .

Table 4. Correlations between social-psychological adaptation parameters and IDP components among 
disabled adolescents in clusters 2,3,4 $(p<0,05)$ parameters

\section{Social-psychological adaptation}

Cluster 2

\begin{tabular}{lll}
\hline Cluster 2 & & 0.47 \\
\hline Dominance behavior & & \\
\hline Cluster 3 & $-0,55$ & \\
\hline Acceptance of others & $-0,39$ & \\
\hline Internality & & 0.50 \\
\hline Cluster 4 & & \\
\hline Emotional comfort & & \\
\hline
\end{tabular}

We observe statistically significant negative correlations between the physical-sensitive IDP component and one's acceptance of others and internality - an individual's physical comfort and lower levels of their fixation on physical sensations both encourage them to seek social interaction, contacts and enhance their personal responsibility and maturity. Cluster 4 is characterized by a positive correlation between the cognitive component and emotional comfort. This suggests that this cluster (females are prevalent here) finds emotional comfort by growing their disorder awareness.

\section{Discussion}

We identify four IDP variants based on the content of the components. They are distinguished by the components' content and ratio and characterized by specificities of respondents' social-psychological adaptation. We can offer several guidelines for further psychological work aimed to optimise adaptation processes.

The Cognitive-emotional variant is characterized by one's sufficient awareness of their disorder and emotional experiences, which are related to it. This group is less susceptible to maladaptation than the others. However, their social adaptation is negatively correlated with the motivational and emotional components. This may imply a «psychological» cost for successful adaptation - they suppress emotions and reject to continue efforts to overcome disorders. High levels of the group's motivation to overcome their defect are distinguished by emotional discomfort, challenged self-acceptance and that of others. These respondents are characterized by their preference for external control and non-dominant behavior. We can conclude that abundant emotional experiences caused by their defects are likely to determine their social maladaptation, low level of self-satisfaction, emotional discomfort, and enhanced demand for support. 
This interpretation is based on the correlation between low indices in the emotional component and high levels of self-acceptance and emotional comfort. We observed high levels of determination to overcome their disorders and that of emotional tension, as well as challenged self-acceptance and interpersonal communication that hinder adaptation processes.

In case of hindered social-psychological adaptation in the cluster, psychotherapy is to involve the analysis of a patient's emotional states, raising their awareness of the opportunities and limitations they face to overcome their disabilities. Thus, it is important to teach a to overcome strong emotions, find a strategy to express them in a socially acceptable way.

The sensitive-cognitive variant implies intense physical sensations, excessive sensitivity to bodily discomfort, and undifferentiated emotional experiences. The cognitive component (one's awareness of their disorder) is correlated to dominant behavior. Similarly to the cognitive-emotional variant, this is likely to indicate one's defense and compensation mechanism. This strategy effectively deals with the problem of self-rejection and proves more successful in Cluster 1 than Cluster 2, where self-rejection is persistent. Therapeutic focus may be on a patient's emotional experiences, analysis and regulation of those, their relation to physical sensations, and seeking strategies for social leadership. Encouraging a conscious attitude to emotional experiences and developing an ability to interpret them is critical for this group.

The sensitive-emotional variant is distinguished by hypochondriacal responses, aggravation and deep reluctance to develop disorder awareness. This IDP variant most strongly implies adaptation problems and is characterized by moderate levels of maladaptation and self-rejection. An individual's fixation on their physical sensations may cause challenged socialization, rejection of their environment, and a low level of responsibility for their own life. This variant most urgently requires systematic psychological support and therapy, such as minimisation of fixation on physical sensations, explanation of disorder potential benefits and personality maturation.

The balanced variant is characterized by moderate indices and evenly distributed values. It demonstrates sufficient adaptability. Adaptation is related to respondents' awareness of their disorders, which serves as a basis for emotional comfort. This variant requires general therapeutic support aimed to maintain their adaptability.

\section{Conclusion:}

The results reveal that one's disorder awareness, emotional experiences, physical sensations caused by their 
disorder, and subsequent health limitations may affect their adaptability.

We distinguish 4 IDP variants whose components may differ quantitatively as well as in their ratio. Each IDP component has specific relationships with social-psychological adaptation parameters. Most successful adaptation strategies are correlated to low indices in the physical-sensitive IDP component.

The results also suggest several hypotheses about possible adaptation and maladaptation mechanisms. On the one hand, adolescents' rejection to overcome their disability, suppressed emotions, and preference for dominant behavior may secure self-acceptance and disorder-acceptance for some of them. Growing disorder awareness, i.e. improving indices in the cognitive component, may prove a more effective strategy to enhance adaptability for other adolescents.

\title{
Acknowledgements
}

The reported study was funded by RFBR according to the research project № 19-013-00768A

\author{
Abbreviations \\ IDP internal disorder pattern \\ VI visual impairment \\ HI hearing impairment \\ SSI severe speech impairment \\ MDD mental development disorders
}

\section{References}

Adeeva, T., Tikhonova, I., \& Khazova, S. (2019). Variants of Inward Disorder Pattern and Self-Awareness Features Among Elementary School Children with Different Dysontogenesis Forms. Social welfare interdisciplinary appoach, 9(1), 120-131.

Akinina, E. B. (2015). Self-attitude as a leading psychological and acmeological component in the structure of the personality of deaf and hard of hearing students. Economics of education, 1, 103-107.

Cheong, S. K., Lang, C. P., \& Johnston, L. M. (2018). Self-concept of children with cerebral palsy 
measured using the population-specific my treehouse Self-Concept Assessment. Research in Developmental Disabilities, 73, 96-105.

Dolgova, V. I., \& Vasilenko, E. A. (2016). Development of the criteria base of the study sociopsychological adaptation of the individual. Modern high technologies, 5, 530-534.

Dunaevskaya, E. B. (2016). Psychological features and techniques of teaching adolescents with delayed mental development in terms of inclusive education. Modern scientific researches and works, 7(7), 96-102.

Gaidukevich, E. A. (2011). The problem of the internal picture of the defect in special psychology. Izvestiya RGPU im. A. I. Herzen. Retrieved from: https://cyberleninka.ru/article/n/problemavnutrenney-kartiny-defekta-v-spetsialnoy-psihologii

Hyeran, A., \& Sunhee, L. (2019) Difficulty in returning to school among adolescent leukemia survivors: A qualitative descriptive study. European Journal of Oncology Nursing, v. 38. Retrieved from: http://www.sciencedirect.com/https://doi.org/10.1016/j.ejon.2018.12.008

Katsero, A. A. (2019). To the question of development of an affective-estimative component in I-concept of students with disabilities. Vestnik: Philology and Psychology, 4, 107-110.

Koneva, I. A., \& Kuznetsova, K. E. (2015). On the problem of self-image and self-esteem of younger students with mental retardation. Modern problems of science and education, 2(3), 149-156.

Nalchajyan, A. A. (1988). Social-psychological adjustment of personality: forms, mechanisms and strategies. Yerevan: Yerevan, Publ. House of the Academy of Sciences of Armenia.

O'Connor, C., Kadianaki, I., Maunder, M., \& Mc Nicholas, F. (2018). How does psychiatric diagnosis affect young people's self-concept and social identity? A systematic review and synthesis of the qualitative literature. Social Science \& Medicine, 212, 94-119.

Ramirez Y. Huerta, \& Heredia M. Elena Rivera. (2017). Resilience, family and spiritual resources in caregivers of children with disabilities Journal of Behavior, Health \& Social Issues, 9(2), 70-81.

R. Rooda, L., Zee M., Bosman, R. J., \& Koomen, H. M. Y. (2021). Student-teacher relationships and school engagement: Comparing boys from special education for autism spectrum disorders and regular education. Journal of Applied Developmental Psychology, v. 74. Retrieved from: 
https://www.sciencedirect.com/.\%20https://doi.org/10.1016/j.appdev

Shuvalova, I. N. (2016). Comprehensive support of higher professional education of disabled people. Vestnik of modern science, 3(15), part-2, 114-117.

Shorey, S., \& Debby, E. (2020). The Lived Experiences of Children and Adolescents with NonCommunicable Disease: A Systematic Review of Qualitative Studies. Journal of Pediatric Nursing, 51. Retrieved from: http://www.sciencedirect.com/ https://doi.org/10.1016/j.pedn.2019.12.013

Varsamis, P., \& Agaliotis, I. (2011). Profiles of self-concept, goal orientation, and self-regulation in students with physical, intellectual, and multiple disabilities: Implications for instructional support. Research in Developmental Disabilities, 32, 5, 1548-1555.

Voronova, O. V., \& Gudzovskaya, A. A. (2020). Socio-pedagogical activity on the formation of selfattitude of high school students with hearing disorders. Special education, 1 (57), 5-16.

Vygotskij, L.S. (1983). Collected works in 6 volumes. V. 5. Fundamentals of defectology. Moscow: Pedagogy. 